\title{
Low-molecular-weight Protein Tyrosine Phosphatase Is a Possible Biomarker for Predicting Postoperative Biochemical Recurrence in Prostate Cancer With Negative Surgical Margins
}

\author{
HIROFUMI KUROSE ${ }^{1,2}$, KOSUKE UEDA ${ }^{2}$, REIICHIRO KONDO ${ }^{1}$, \\ SACHIKO OGASAWARA ${ }^{1}$, HIRONORI KUSANO $^{1}$, SAKIKO SANADA $^{1}$, YOSHIKI NAITO $^{3}$, \\ JUN AKIBA ${ }^{3}$, TATSUYUKI KAKUMA ${ }^{4}$, TSUKASA IGAWA ${ }^{2}$ and HIROHISA YANO ${ }^{1}$ \\ ${ }^{1}$ Department of Pathology, Kurume University School of Medicine, Kurume, Japan; \\ ${ }^{2}$ Department of Urology, Kurume University School of Medicine, Kurume, Japan; \\ ${ }^{3}$ Department of Diagnostic Pathology, Kurume University Hospital, Kurume, Japan; \\ ${ }^{4}$ Biostatistics center, Kurume University School of Medicine, Kurume, Japan
}

\begin{abstract}
Background/Aim: For prostate cancer, positive surgical margins are considered an important predictor of biochemical recurrence. However, biochemical recurrence is observed in approximately $20 \%$ of cases, even with negative surgical margins, and some cases require salvage therapy. The elevated expression of low-molecular-weight protein tyrosine phosphatase (LMW-PTP, MW $18 \mathrm{kDa}$ ) is associated with a poor prognosis of certain cancers. In this study, we investigated whether the LMW-PTP expression levels could be used as a biomarker of recurrence in prostate cancer with negative surgical margins. Materials and Methods: The subjects of this retrospective study were 119 patients who underwent total prostatectomy with negative resection margins. LMW-PTP expression was categorized either as a highexpression group or as a low-expression group bye two pathologists. Subsequently, we examined the relationship between LMW-PTP expression levels and clinicopathological factors including biochemical recurrence. Results: Evaluation of the immunostained samples by two pathologists was highly reliable, with an Intraclass correlation (ICC) score for two distinct measurements of 0.77 and 0.98 , respectively. Seventythree patients $(61.3 \%)$ were placed in the LMW-PTP high expression group; and 46 patients (38.7\%) were placed in the low expression group. The log-rank test revealed early biochemical recurrence in the high LMW-PTP expression group $(p=0.0001)$. In addition, pathological T stage $(p=0.004)$,
\end{abstract}

Correspondence to: Hirofumi Kurose, Department of Urology, Kurume University School of Medicine, 67 Asahimachi, Kurume, 830-0011, Japan. Tel: +81 942317546, Fax: +81 942320905, e-mail: kurose_hirofumi@med.kurume-u.ac.jp

Key Words: LMW-PTP, prostate cancer, protein phosphatase, biomarker, biochemical recurrence. lymphatic invasion $(p=0.0456)$, Ki-67 labeling index $(p=0.0002)$, and biochemical recurrence $(p<0.0001)$ were more frequently identified in the LMW-PTP high expression group. Furthermore, multivariate analyses revealed that a high LMW-PTP expression level was an independent prognostic factor for biochemical recurrence (HR=3.14, 95\% CI=1.378.07, $p=0.0057)$. In addition, Ki-67 labeling indices were significantly higher in the high-expression group compared to the low-expression group $(p<0.0001)$. Conclusion: LMW-PTP can be assessed using a single immunostaining protocol in a highly reproducible fashion. Tt may, thus, be applied clinically to establish the required postoperative follow-up period and determine the necessity for salvage therapy in cases of prostate cancer with negative surgical margins. LMW-PTP has the potential to be a highly useful prognostic biomarker and a therapeutic target in conjunction with other factors, such as the Gleason Score, the pathological T stage and the PSA level.

Prostate cancer is the most common type of cancer in men in developed countries. In the United States, one in five new cases of diagnosed cancer is in the prostate, while in Japan, the increasingly widespread use of prostate-specific antigen (PSA) testing has led to prostate cancer becoming the most prevalent type of cancer in men in 2016 (1). Treatment options for localized prostate cancer include radical prostatectomy (2), radiotherapy (external \& internal radiation) (3), and active surveillance (4). However, changes in surgical procedures (from open surgery to endoscopic/ robot-assisted surgery) have led to an increase in the number of patients undergoing prostatectomy as a radical therapy (5).

When surgery is selected to treat localized prostate cancer, the prognosis is generally good. However, the postoperative biochemical recurrence is happening for a $16-31 \%$ in 5 years and for a $25-53 \%$ in 10 years $(6,7)$. A portion of these cases develop castrate-resistant prostate cancer following clinical 
recurrence, which often results in an unfortunate outcome (8). Thus, biochemical recurrence is one of the factors used to justify the use of salvage therapies such as endocrine therapy and radiotherapy. Several studies have identified a variety of predictive factors for a biochemical recurrence (912). Significant factors include a designation of positive surgical margins (RM1)(13), a preoperative PSA score (10, 11), a Gleason score at prostatectomy, and pathological staging. Of these, positive surgical margins (RM1) is the most important predictive factor for the biochemical recurrence (recurrence rate: 1.5-6.0x) (14). Even when negative surgical margins (RM0) are identified, which occurs in a large percentage of all patients, biochemical recurrence subsequently develops in approximately $20 \%$ of such cases, and these patients often require salvage therapy (15). Despite this, there are few reports presenting effective biomarkers that can be used to predict such cases. With the widespread use of PSA screening, prostate cancer is discovered at an earlier stage and thus therapeutic intervention is performed sooner (16). This has led to an increase in the percentage of cases with negative surgical margins (62-82\%) (17). From all these, it is extremely important to identify a prognostic biomarker in cases of negative surgical margins, which comprise most of localized prostate cancer cases.

Low-molecular-weight protein tyrosine phosphatase (LMW-PTP) is an $18-\mathrm{kDa}$ enzyme that is encoded by ACP1 located on chromosome $2 \mathrm{p} 25$. It is normally expressed in a variety of human tissues and controls cell proliferation by dephosphorylating, and thus deactivating, a variety of tyrosine kinase receptors and docking proteins (18).

In recent years, LMW-PTP has also been found to be involved in cancer with related changes in expression. In colon cancer and neuroblastoma increased total LMW-PTP mRNA expression correlates with unfavorable outcome, while there was no correlation in lung cancer (19). Thus, it is considered an important factor involved with cancer progression. Protein phosphatases are generally involved in the regulation of intracellular signal transmissions, cell proliferation and cell differentiation, by dephosphorylating target proteins as a counterpart to protein kinases, and through this process they supposedly work towards suppressing tumor growth and development. However, in recent years it has been reported that some protein phosphatases promote tumor proliferation in a number of cancers (20). LMW-PTP is one of these protein phosphatases. Increased tumor expression of LMW-PTP in cancers such as colorectal cancer, breast cancer, and neuroblastoma has been reported to lead to poor prognosis $(19,21,22)$. Additionally, it was recently reported that high expression of LMW-PTP is a factor related to poor prognosis in prostate cancer as well, suggesting that it may be an effective prognostic prediction factor $(23,24)$. Unfortunately, there have been no investigations on whether a high expression of LMW-PTP can be utilized as a biomarker to predict recurrence in cases of localized prostate cancer, and particularly, in cases of postprostatectomy with negative surgical margins (RM0). In this study we evaluated LMW-PTP expression in cases of prostate cancer with negative surgical margins who had undergone surgical resection. We also investigated the feasibility of using serum PSA value in conjunction with Gleason score and various histopathological factors, as a predictive factor of biochemical recurrence.

\section{Patients and Methods}

This study was approved by the Research Ethics Committee of the Kurume University, which conforms to the guidelines of the Declaration of Helsinki (Number 17260).

Patients and tissue samples. The subjects of this retrospective study were 119 cases with negative surgical margins who were selected from 241 cases that underwent prostatectomy at the Kurume University Hospital (Kurume, Japan) between January 2007 and December 2011. As part of this study, the pathological diagnoses of the subjects were re-examined. Histopathological evaluations were performed by three pathologists (H.K., R.K. and H.Y.). Pathological diagnosis was performed according to the 2016 WHO Classification of Tumors of the Urinary System and Male Genital Organs (25). All patients were diagnosed with prostatic adenocarcinoma. The following were exclusion criteria: i) hormonal therapy and/or radiotherapy before surgery, ii) unclear resection margins (RM) when the pathological diagnosis was reexamined, iii) stage pT0 during surgery, and iv) inadequate specimen for tissue microarray (TMA).

Immunohistochemical analysis. Specimens for TMA were stained from 119 prostate cancer patients. Immunostaining of 2 TMA samples per patient was performed to resolve the high degree of heterogeneity of prostate cancer. Paraffin-embedded tissue samples were cut to a thickness of $4 \mu \mathrm{m}$, examined on a coated glass-slide, and were labeled with anti-LMW-PTP (sc-100343, 1:100; Santa Cruz Biotechnologies, Dallas Tx, USA) and anti-Ki-67 antibodies (NCL-Ki67-MM1; dilution 1:200; Leica Biosystems, Nussloch, Germany) using a BenchMark ULTRA (Ventana Automated Systems, Inc., Tucson, AZ, USA). Briefly, the slides were heattreated using Ventana's ULTRA cell conditioning 1 retrieval solution (CC1; Ventana Automated Systems, Inc.) for 36 min at $95^{\circ} \mathrm{C}$ and were incubated with anti-LMW-PTP and anti-Ki-67 antibodies for $32 \mathrm{~min}$ at $37^{\circ} \mathrm{C}$. An automated system with a Ventana UltraVIEW 3,3'-diaminobenzidine (DAB) detection kit was used. We considered only the cytoplasmic expression of LMW-PTP as positive, and only the nuclear expression of Ki-67 as positive. Representative IHC microphotographs of LMW-PTP staining are shown in Figure 1. Expression was classified as: i) 0, when very low or with no staining, ii) 1 , when intensity was just above background level, iii) 2 , when clearly visible at a low magnification, and iv) 3, when striking at a low magnification. All immunohistochemical analyses were evaluated by two experienced pathologists who were unaware of the patients' clinical condition. The scores of the two pathologists were added, and each patient was given a total expression score consisting of 13 levels from 0 to 12 . 

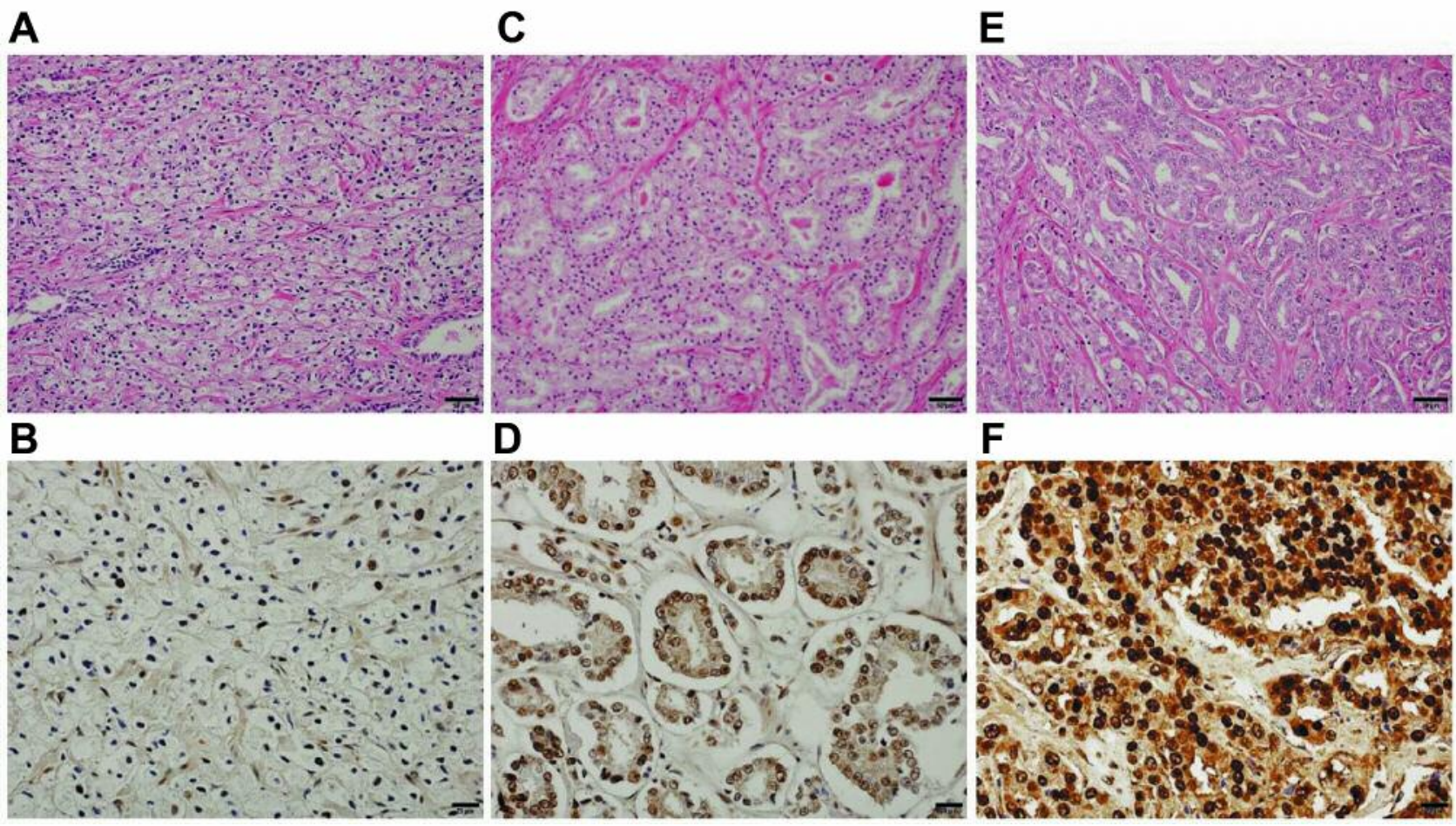

Figure 1. Histological findings. Hematoxylin and eosin staining (upper panels; $a, c, e: \times 200$ ), LMW-PTP immunohistochemistry (middle panels; $b$, $d, f: \times 200)$. We only considered cytoplasmic expression of LMW-PTP as positive. Since most epithelial cells were positive for the staining, we focused on LMW-PTP intensity. Expression was classified as 1 when intensity was just above background level (b), 2 when clearly visible at low magnification $(d)$ and 3 when striking at low magnification $(f)$.

Statistical analysis. We examined the association between LMWPTP expression and clinicopathological characteristics, such as: i) age at diagnosis, ii) serum PSA level at diagnosis, iii) D'Amico risk stratification, iv) Gleason Score at RP, v) pathological T stage, vi) lymphatic invasion, vii) peripheral nerve invasion, viii) Ki-67 LI, and ix) biochemical recurrence, using the $\chi^{2}$ test or Fisher's exact test. Cancer survival analysis was performed using the KaplanMeier method, log-rank test, and Cox's proportional hazards model. The threshold for statistical significance was set at $p<0.05$ Biochemical recurrence was defined as an increase in PSA level over $0.2 \mathrm{ng} / \mathrm{ml}$ after two different measurements at least 3 months apart. Finally, because cell proliferation affects the relationship between LMW-PTP expression and prognosis, we used Spearman rank correlation testing to investigate the correlation between Ki-67 LI, which is an index of cell proliferation, and LMW-PTP. The statistical software used was JMP ${ }^{\circledR}$ Pro 13 (SAS Institute Inc., Cary, NC, USA).

\section{Results}

Patients' characteristics. The clinicopathological characteristics of 119 patients are summarized in Table I. The median postoperative follow-up period was 72 months (range, 39-84). The median age was 67 years (range, 53-77) and median PSA level at initial diagnosis was $6.44 \mathrm{ng} / \mathrm{ml}$ (range, 2.13-62.34).
D'Amico risk stratification was low in 31 patients $(26.0 \%)$, intermediate in 56 patients $(47.1 \%)$, and high in 32 patients $(26.9 \%)$. Gleason Scores at prostatectomy were $\leq 6$ in 20 patients $(16.8 \%), 3+4=7$ in 49 patients $(41.2 \%), 4+3=7$ in 38 patients $(31.9 \%)$, and $\geq 8$ in 12 patients $(10.1 \%)$. Pathological stages were $\mathrm{T} 2 \mathrm{a}, \mathrm{b}$ in 22 patients $(18.6 \%)$, T2c in 77 patients (65.3\%), and T3 in 19 patients (16.1\%). The numbers of patients with lymphatic and peripheral nerve invasion were 4 (3.4\%) and $41(34.5 \%)$, respectively. Overall, 44 patients $(37.0 \%)$ experienced biochemical recurrence.

Immunohistochemical analysis of LMW-PTP expression. The distribution of LMW-PTP expression score is shown in Figure 2. The evaluation of immunostained samples by the two pathologists was highly reliable and reproducible, with an intraclass correlation coefficient (ICC) for two distinct measurements of 0.77 and 0.98 (excellent), respectively. By constructing a receiver-operating characteristic curve, LMWPTP expression was categorized into either a high expression group (score: $\geq 5$ ) or a low expression group (score: $\leq 4$ ). Of the 119 patients, $73(61.3 \%)$ were placed in the LMW-PTP high expression group and $46(38.7 \%)$ were placed in the low LMW-PTP expression group. 
Table I. Patient characteristics.

\begin{tabular}{lc}
\hline Parameter & \\
\hline Patients, no. & 119 \\
Age at diagnosis [years], median (range) & $67(53-77)$ \\
PSA level at diagnosis [ng/ml] & \\
Total, median (range) & $6.44(2.13-62.34)$ \\
$<10$ & $95(79.8 \%)$ \\
$>10$ & $24(20.2 \%)$ \\
D'Amico risk stratification, no. (\%) & \\
low & $31(26.0 \%)$ \\
intermediate & $56(47.1 \%)$ \\
high & $32(26.9 \%)$ \\
Gleason score, no. $(\%)$ & \\
$\leq 6$ & $20(16.8 \%)$ \\
$3+4=7$ & $49(41.2 \%)$ \\
$4+3=7$ & $38(31.9 \%)$ \\
$\geq 8$ & $12(10.1 \%)$ \\
Pathological T stage, no. $(\%)$ & \\
T2a, b & $22(18.6 \%)$ \\
T2c & $77(65.3 \%)$ \\
T3 & $19(16.1 \%)$ \\
Lymphatic invasion, no. $(\%)$ & $4(3.4 \%)$ \\
Peripheral nerve invasion, no. (\%) & $41(34.5 \%)$ \\
Ki-67 labelling index (\%), no. $(\%)$ & \\
$<1$ & $89(74.8 \%)$ \\
$1-5$ & $22(18.5 \%)$ \\
$>5$ & $8(6.7 \%)$ \\
Follow up time [months], median (quartile) & $72(39-84)$ \\
Biochemical recurrence, no. $(\%)$ & \\
Presence & $44(37.0 \%)$ \\
None & $75(63.0 \%)$ \\
\hline & \\
\hline & \\
\hline &
\end{tabular}

no.: Number.

Association between LMW-PTP expression and clinicopathological characteristics. The association between LMWPTP expression and clinicopathological characteristics are summarized in Table II. Pathological T stage $(p=0.004)$, lymphatic invasion $(p=0.0456)$, Ki-67 LI $(p=0.0002)$, and biochemical recurrence $(p<0.0001)$ were more frequently identified in the LMW-PTP high expression group. However, there was no association between LMW-PTP expression and the Gleason Score $(p=0.3334)$.

Identification of LMW-PTP as a biomarker of prostatic biochemical recurrence. The time to biochemical recurrence was significantly shorter in the high LMW-PTP expression group compared to the low LMW-PTP expression group $(p=0.0001)$ (Figure 3). Univariate analysis for the time to biochemical recurrence revealed that: i) LMW-PTP expression (high vs. low; $\mathrm{HR}=4.20,95 \% \mathrm{CI}=1.98-10.3, p<0.0001$ ), ii) pathological $\mathrm{T}$ stage (T2a,b vs. T2c; $\mathrm{HR}=1.23,95 \% \mathrm{CI}=0.54-$ 3.14: T2a,b vs. T3; HR=5.40, 95\% CI=2.15-14.9, $p=0.0002)$ and iii) Ki-67 LI (<1\% vs. 1-5\%; HR=1.06, 95\% CI=0.43-2.28: $<1 \%$ vs. $>5 \%$; $\mathrm{HR}=3.77,95 \% \mathrm{CI}=1.41-8.56, p=0.0388)$ were all significant predictors for biochemical recurrence (Table III).
Table II. Association between LMW-PTP expression and clinicopathological characteristics.

\begin{tabular}{|c|c|c|c|}
\hline Parameter & $\begin{array}{l}\text { Low } \\
\text { expression of } \\
\text { LMW-PTP, } \\
\text { no. }(\%)\end{array}$ & $\begin{array}{l}\text { High } \\
\text { expression of } \\
\text { LMW-PTP, } \\
\text { no. }(\%)\end{array}$ & $p$-Value \\
\hline Patients, no. & $46(38.7 \%)$ & $73(61.3 \%)$ & \\
\hline $\begin{array}{l}\text { Age at diagnosis [years], } \\
\text { median (range) } \\
\text { PSA level at diagnosis } \\
{[\mathrm{ng} / \mathrm{ml}]}\end{array}$ & $68(55-75)$ & $66(53-77)$ & 0.2357 \\
\hline Total, median (range) & $6.25(2.13-62.34)$ & $6.91(4.29-45.29)$ & 0.7797 \\
\hline$<10$ & $36(78.3 \%)$ & $59(80.8 \%)$ & - \\
\hline$>10$ & $10(21.7 \%)$ & $14(19.2 \%)$ & - \\
\hline Gleason score & & & 0.3334 \\
\hline$\leq 6$ & $10(21.7 \%)$ & $10(13.7 \%)$ & - \\
\hline $3+4=7$ & $16(34.8 \%)$ & $33(45.2 \%)$ & - \\
\hline $4+3=7$ & $17(37.0 \%)$ & $21(28.8 \%)$ & - \\
\hline$\geq 8$ & $3(6.5 \%)$ & $9(12.3 \%)$ & - \\
\hline Pathological T stage & & & $0.004 *$ \\
\hline $\mathrm{T} 2 \mathrm{a}, \mathrm{b}$ & $13(28.3 \%)$ & $9(12.5 \%)$ & - \\
\hline $\mathrm{T} 2 \mathrm{c}$ & $32(69.6 \%)$ & $45(62.5 \%)$ & - \\
\hline $\mathrm{T} 3$ & $1(2.1 \%)$ & $18(25.0 \%)$ & - \\
\hline $\begin{array}{l}\text { Presence of lymphatic } \\
\text { invasion }\end{array}$ & $0(0.0 \%)$ & $4(5.5 \%)$ & $0.0456^{*}$ \\
\hline $\begin{array}{l}\text { Presence of peripheral } \\
\text { nerve invasion }\end{array}$ & $15(32.6 \%)$ & $26(35.6 \%)$ & 0.7363 \\
\hline Ki-67 labeling index (\%) & & & $0.0002 *$ \\
\hline$<1$ & $43(93.5 \%)$ & $46(63.0 \%)$ & - \\
\hline $1-5$ & $3(6.5 \%)$ & $20(27.4 \%)$ & - \\
\hline$>5$ & $0(0.0 \%)$ & $7(9.6 \%)$ & - \\
\hline \multicolumn{4}{|l|}{$\begin{array}{l}\text { Biochemical recurrence } \\
<0.0001 *\end{array}$} \\
\hline Presence & $7(15.2 \%)$ & $37(51.4 \%)$ & - \\
\hline None & $39(84.8 \%)$ & $35(48.6 \%)$ & - \\
\hline
\end{tabular}

no.: Number.

Multivariate analysis demonstrated that pathological T stage (T2a,b vs. T2c; HR=1.02, 95\% CI=0.43-2.75: T2a,b vs. T3; $\mathrm{HR}=2.87,95 \% \mathrm{CI}=1.05-8.54, p=0.021)$ as well as the LMWPTP expression levels (high vs. low; $\mathrm{HR}=3.14$, 95\% $\mathrm{CI}=1.37$ $8.07, p=0.0057$ ) were independent poor prognostic factors for biochemical recurrence (Table III).

Correlation between LMW-PTP expression and Ki-67 index. Spearman's ranked correlation analysis revealed a coefficient of $0.443(p<0.0001)$ as the standard of significance, indicating a strong positive correlation between LMW-PTP and Ki-67 expression.

\section{Discussion}

The resection margin status is an important prognosis predictor following prostatectomy (14). However, although factors for negative surgical margins, such as the Gleason Score, the 


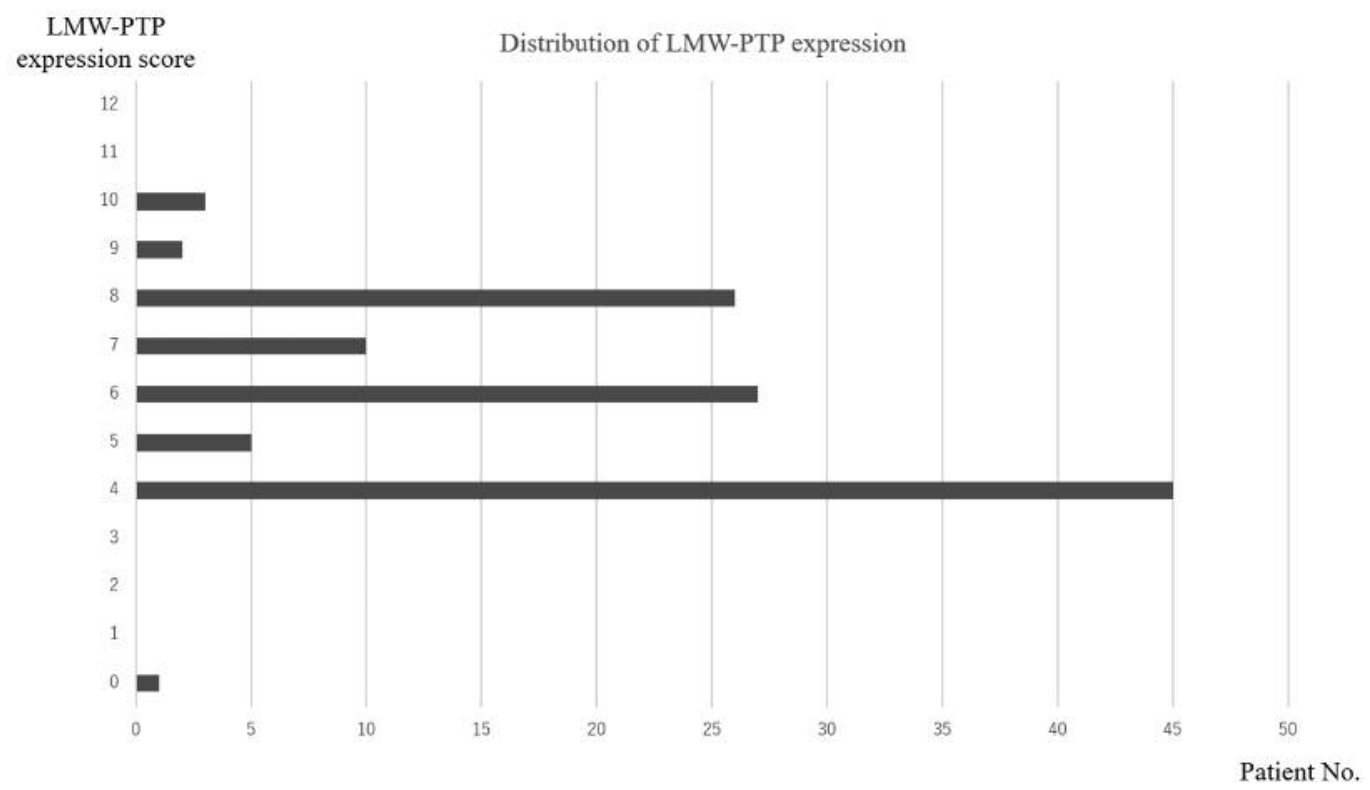

Figure 2. Score map of LMW-PTP expression in 119 cases of prostatic cancer.

pathological T stage, the preoperative PSA level, and the PSA mass ratio have been reported to be prognostic, there is as yet no consensus on their usefulness $(26,27)$. In this study, we evaluated the LMW-PTP expression levels in biopsies from prostate cancer with negative surgical margins and assessed the feasibility of using the results as a predictive factor with respect to biochemical recurrence. The results of this study are the first to suggest that patients in the LMW-PTP high-expression group exhibit a poor prognosis compared to those in the lowexpression group, and the results of univariate and multivariate analyses also suggest that high LMW-PTP expression may be a useful prognostic factor for biochemical recurrence in case of negative surgical margins. The Ki-67 LI in the LMW-PTP high-expression group was significantly higher compared to the low-expression group, and our results indicate that LMW-PTP is related to cells' proliferative ability. In addition, based on the ICC, the immunostaining assessments of LMW-PTP conducted by two pathologists had a high degree of reliability and reproducibility. Based on these findings, histological evaluation of LMW-PTP appears to be useful regarding the postoperative treatment strategy.

Prostate cancer, which is a typical example of a cancer with a high degree of heterogeneity, both suppresses and stimulates the functions of multiple signal transduction pathways to varying levels, with the final output of these processes giving prostate cancer its characteristics. One such product of signal transduction, protein tyrosine kinase (PTK), is known to have functional and expression-related abnormalities in many malignancies. For example, some findings suggest that the increased phosphorylation of HER-2 in cases of prostate cancer

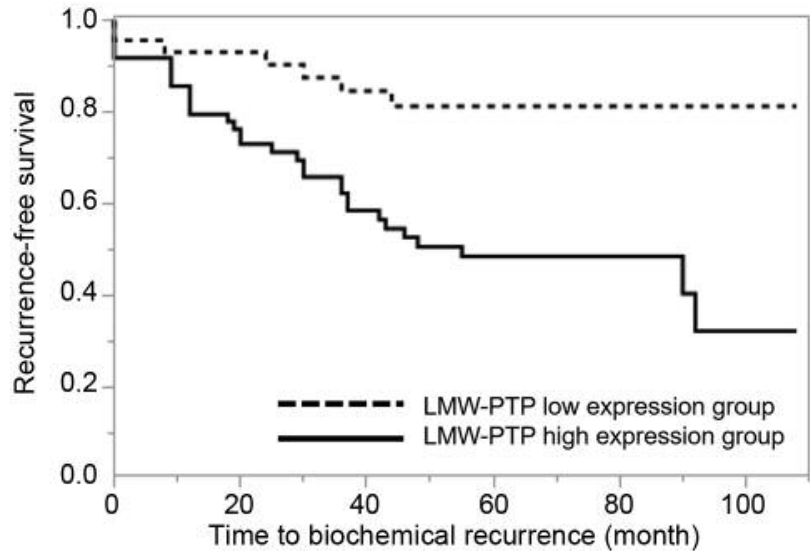

Figure 3. Kaplan-Meier curves for time to biochemical recurrence stratified by LMW-PTP expression with negative surgical margins. Time to biochemical recurrence was significantly shorter for patients with high LMW-PTP expression compared to patients with low LMW-PTP expression ( $p=0.0001$, Kaplan-Meier analysis).

is closely related to androgen-independent tumor cell proliferation (28-30). One substance that plays a role in the negative regulation of tyrosine phosphorylation is protein tyrosine phosphatase (PTP). Although Igawa et al. have reported that prostatic acid phosphatase is involved in the negative control of prostate cancer cell proliferation through regulation of PTKs, there are far fewer reports on PTPs in prostate cancer than there are on PTKs $(31,32)$, hence, the details of the mechanism of action remain largely unknown. 
Table III. Univariate and multivariate analysis for time to biochemical recurrence.

\begin{tabular}{|c|c|c|c|c|}
\hline \multirow[b]{2}{*}{ Parameter } & \multicolumn{2}{|c|}{ Univariate } & \multicolumn{2}{|c|}{ Multivariate } \\
\hline & $\mathrm{HR}(95 \% \mathrm{CI})$ & $p$-Value & HR $(95 \%$ CI $)$ & $p$-Value \\
\hline Age at diagnosis, $>67$ [years] & $1.76(0.97-3.25)$ & 0.062 & & \\
\hline PSA level at diagnosis, $>10[\mathrm{ng} / \mathrm{ml}]$ & $1.58(0.76-3.04)$ & 0.206 & & \\
\hline Gleason score & & 0.263 & & \\
\hline$\leq 6$ & 1 & - & & \\
\hline $3+4=7$ & $1.05(0.44-2.91)$ & - & & \\
\hline $4+3=7$ & $1.15(0.46-3.25)$ & - & & \\
\hline$\geq 8$ & $2.66(0.88-8.31)$ & - & & \\
\hline Pathological T stage & & $0.0002 *$ & & $0.021 *$ \\
\hline $\mathrm{T} 2 \mathrm{a}, \mathrm{b}$ & 1 & - & 1 & - \\
\hline $\mathrm{T} 2 \mathrm{c}$ & $1.23(0.54-3.14)$ & - & $1.02(0.43-2.75)$ & - \\
\hline $\mathrm{T} 3$ & $5.40(2.15-14.9)$ & - & $2.87(1.05-8.54)$ & - \\
\hline Presence of lymphatic invasion & $1.48(0.24-4.85)$ & 0.557 & & \\
\hline Presence of peripheral nerve invasion & $1.10(0.59-2.19)$ & 0.766 & & \\
\hline Ki-67 labeling index $(\%)$ & & $0.0388^{*}$ & & 0.359 \\
\hline$<1$ & 1 & - & 1 & - \\
\hline $1-5$ & $1.06(0.43-2.28)$ & - & $1.14(0.51-2.91)$ & - \\
\hline$>5$ & $3.77(1.41-8.56)$ & - & $1.94(0.70-4.56)$ & - \\
\hline High expression of LMW-PTP & $4.20(1.98-10.3)$ & $<0.0001 *$ & $3.14(1.37-8.07)$ & $0.0057^{*}$ \\
\hline
\end{tabular}

HR: Hazard ratio; CI: confidence interval.

LMW-PTPs are a group of 18-kDa enzymes that belong to the class II cysteine-based PTPs and are expressed abundantly in tissues $(33,34)$. LMW-PTP has been largely considered a negative regulator of growth factor-induced cell proliferation, due to its interaction with molecules such as the plateletderived growth factor receptor (35), $\beta$-catenin (36), Janus kinase 2 (37), signal transducer and activator of transcription 5 (STAT5) (38), the fibroblast growth factor receptor (39), and the insulin receptor (40). Only in few instances it acts as a positive regulator, such as the Ephrin Receptor A2 (EphA2), which seems to be involved in the regulation of carcinogenesis through LMW-PTP signaling $(20,41,42)$. Hyperexpression of EphA2, which is a receptor tyrosine kinase, has a higher enzymatic activity when in the dephosphorylated state compared to its phosphorylated state. It has been reported, that when EphA2 is dephosphorylated, it regulates tumor cell proliferation, migration, infiltration, and other cell behaviors, while in a large number of cancers it functions as a positive regulator of the tumor $(43,44)$. LMW-PTP is an important negative regulator of EphA2 phosphorylation, and therefore, it is involved in the proliferation, invasion, and migration of tumors through the dephosphorylation of EphA2 (18). The Ki$67 \mathrm{LI}$ is recognized as a marker of cell proliferation, and $\mathrm{Ki}$ 67 LI scores were significantly higher in the LMW-PTP highexpression group, compared to the low-expression group in this study. This suggests a positive correlation between LMWPTP with cell proliferative capacity. These findings indicate that cell proliferation may also be induced in prostate cancer as a result of dephosphorylation of EphA2. There are no previous studies in prostate cancer that show a correlation between LMW-PTP and EphA2 expression, but this would be an interesting field of exploration for the future.

In the present study, LMW-PTP was found to be a prognostic factor, whereas serum PSA values and Gleason scores were not reliable, despite the Gleason score being an important prognostic factor used in routine clinical practice. Surprisingly, in this study, no significant correlation was observed between LMW-PTP expression and the Gleason score. The Gleason score is a metric used in the histological evaluation of tumor cells $(45,46)$. However, it is difficult to characterize the biological properties of tumor cells based on tissue morphology alone. In this study, the early biochemical recurrence observed in the LMW-PTP high-expression group and high LMW-PTP expression level strongly correlated with Ki-67 expression. In the patients we examined, LMWPTP expression was found to be a promising biomarker for evaluating malignancies that cannot be identified based on tissue morphology alone. Overall, our findings indicate the feasibility of using LMW-PTP expression as a biochemical recurrence factor in combination with the Gleason score.

In general, biochemical recurrence serves as an indicator of the early stages of relapse, since local recurrence and distant metastasis may occur after biochemical recurrence $(47,48)$. The fact that a large number of tumor cells strongly expressing LMW-PTP correlate with the tumor proliferation ability may suggest that these cells exhibit tumor characteristics that are likely to result in recurrence. Since LMW-PTP expression in resected specimens is a strong predictor of biochemical 
recurrence, the extent of LMW-PTP expression could provide useful information for the determination of post-operative treatment strategy. The value of LMW-PTP expression as a predictive biomarker may though be hindered, depending on the size of the biopsy tissue that could be difficult to assess as well as due to cancer heterogeneity. For this reason, our future aim is to measure LMW-PTP expression in different size prostate biopsy tissues and add this assessment to the initial diagnostic tests, in order to better explore the clinical applications of this biomarker. The results of immunostaining of LMW-PTP conducted in this study suggest that LMW-PTP is a useful predictive factor for biochemical recurrence in cases of prostate cancer with negative surgical margins. LMWPTP expression can be assessed using a single immunostaining protocol, and the assessments are highly reproducible. Thus, it might be applied in clinical practice to establish the required postoperative follow-up period and determine the necessity of salvage therapy in cases of prostate cancer with negative surgical margins. LWM-PTP has the potential to be a highly useful prognostic biomarker in conjunction with the Gleason score, the pathological T stage and the PSA level. We hope to conduct further studies to correlate LMW-PTP with EphA2 in cases of prostate cancer.

\section{Conflicts of Interest}

All Authors have declared no conflicts of interest.

\section{References}

1 Siegel RL, Miller KD and Jemal A: Cancer statistics, 2016. CA Cancer J Clin 66(1): 7-30, 2016.

2 Wilt TJ, Brawer MK, Jones KM, Barry MJ, Aronson WJ, Fox S, Gingrich JR, Wei JT, Gilhooly P, Grob BM, Nsouli I, Iyer P, Cartagena R, Snider G, Roehrborn C, Sharifi R, Blank W, Pandya P, Andriole GL, Culkin D and Wheeler T: Radical prostatectomy versus observation for localized prostate cancer. N Engl J Med 367(3): 203-213, 2012.

3 Hou Z, Li G and Bai S: High dose versus conventional dose in external beam radiotherapy of prostate cancer: A meta-analysis of long-term follow-up. J Cancer Res Clin Oncol 141(6): 10631071, 2015.

4 Klotz L, Vesprini D, Sethukavalan P, Jethava V, Zhang L, Jain S, Yamamoto T, Mamedov A and Loblaw A: Long-term followup of a large active surveillance cohort of patients with prostate cancer. J Clin Oncol 33(3): 272-277, 2015.

5 Lowrance WT, Eastham JA, Savage C, Maschino AC, Laudone VP, Dechet CB, Stephenson RA, Scardino PT and Sandhu JS: Contemporary open and robotic radical prostatectomy practice patterns among urologists in the united states. J Urol 187(6): 2087-2092, 2012.

6 Han M, Partin AW, Pound CR, Epstein JI and Walsh PC: Longterm biochemical disease-free and cancer-specific survival following anatomic radical retropubic prostatectomy. The 15year johns hopkins experience. Urol Clin North Am 28(3): 555565,2001
7 Hull GW, Rabbani F, Abbas F, Wheeler TM, Kattan MW and Scardino PT: Cancer control with radical prostatectomy alone in 1,000 consecutive patients. J Urol 167(2 Pt 1): 528-534, 2002.

8 Zumsteg ZS, Spratt DE, Romesser PB, Pei X, Zhang Z, Polkinghorn W, McBride S, Kollmeier M, Yamada $\mathrm{Y}$ and Zelefsky MJ: The natural history and predictors of outcome following biochemical relapse in the dose escalation era for prostate cancer patients undergoing definitive external beam radiotherapy. Eur Urol 67(6): 1009-1016, 2015.

9 D'Amico AV, Whittington R, Malkowicz SB, Schultz D, Blank K, Broderick GA, Tomaszewski JE, Renshaw AA, Kaplan I, Beard CJ and Wein A: Biochemical outcome after radical prostatectomy, external beam radiation therapy, or interstitial radiation therapy for clinically localized prostate cancer. Jama 280(11): 969-974, 1998.

10 D'Amico AV, Chen MH, Roehl KA and Catalona WJ: Preoperative psa velocity and the risk of death from prostate cancer after radical prostatectomy. N Engl J Med 351(2): 125-135, 2004.

11 Budaus L, Isbarn H, Eichelberg C, Lughezzani G, Sun M, Perrotte P, Chun FK, Salomon G, Steuber T, Kollermann J, Sauter G, Ahyai SA, Zacharias M, Fisch M, Schlomm T, Haese A, Heinzer H, Huland H, Montorsi F, Graefen M and Karakiewicz PI: Biochemical recurrence after radical prostatectomy: Multiplicative interaction between surgical margin status and pathological stage. J Urol 184(4): 1341-1346, 2010.

12 Negishi T, Kuroiwa K, Hori Y, Tomoda T, Uchino H, Tokuda N, Furubayashi N, Nagase K, Iwai $\mathrm{H}$ and Nakamura M: Predictive factors of late biochemical recurrence after radical prostatectomy. Jpn J Clin Oncol 47(3): 233-238, 2017.

13 Ohori M, Kattan MW, Koh H, Maru N, Slawin KM, Shariat S, Muramoto M, Reuter VE, Wheeler TM and Scardino PT: Predicting the presence and side of extracapsular extension: A nomogram for staging prostate cancer. J Urol 171(5): 18441849; discussion 1849, 2004.

14 Yossepowitch O, Bjartell A, Eastham JA, Graefen M, Guillonneau BD, Karakiewicz PI, Montironi R and Montorsi F: Positive surgical margins in radical prostatectomy: Outlining the problem and its long-term consequences. Eur Urol 55(1): 87-99, 2009.

15 Yossepowitch O, Briganti A, Eastham JA, Epstein J, Graefen M, Montironi $\mathrm{R}$ and Touijer K: Positive surgical margins after radical prostatectomy: A systematic review and contemporary update. Eur Urol 65(2): 303-313, 2014.

16 Desireddi NV, Roehl KA, Loeb S, Yu X, Griffin CR, Kundu SK, Han $M$ and Catalona WJ: Improved stage and grade-specific progression-free survival rates after radical prostatectomy in the psa era. Urology 70(5): 950-955, 2007.

17 Maruyama S, Kikuchi H, Miyajima N, Tsuchiya K, Abe T and Shinohara N: Recurrence of prostate cancer after radical prostatectomy whose pathology was thought to be favorable. Japanese Journal of Urological Surgery 29(8): 1321-1323, 2016.

18 Souza AC, Azoubel S, Queiroz KC, Peppelenbosch MP and Ferreira CV: From immune response to cancer: A spot on the low molecular weight protein tyrosine phosphatase. Cell Mol Life Sci 66(7): 1140-1153, 2009.

19 Malentacchi F, Marzocchini R, Gelmini S, Orlando C, Serio M, Ramponi $G$ and Raugei G: Up-regulated expression of low molecular weight protein tyrosine phosphatases in different human cancers. Biochem Biophys Res Commun 334(3): 875-883, 2005. 
20 Chiarugi P, Taddei ML, Schiavone N, Papucci L, Giannoni E, Fiaschi T, Capaccioli S, Raugei G and Ramponi G: Lmw-ptp is a positive regulator of tumor onset and growth. Oncogene 23(22): 3905-3914, 2004.

21 Ruela-de-Sousa RR, Queiroz KC, Peppelenbosch MP and Fuhler GM: Reversible phosphorylation in haematological malignancies: Potential role for protein tyrosine phosphatases in treatment? Biochim Biophys Acta 1806(2): 287-303, 2010.

22 Hoekstra E, Peppelenbosch MP and Fuhler GM: The role of protein tyrosine phosphatases in colorectal cancer. Biochim Biophys Acta 1826(1): 179-188, 2012.

23 Ruela-de-Sousa RR, Hoekstra E, Hoogland AM, Queiroz KC, Peppelenbosch MP, Stubbs AP, Pelizzaro-Rocha K, van Leenders GJ, Jenster G, Aoyama H, Ferreira CV and Fuhler GM: Lowmolecular-weight protein tyrosine phosphatase predicts prostate cancer outcome by increasing the metastatic potential. Eur Urol 69(4): 710-719, 2016.

24 Ohtaka M, Miyoshi Y, Kawahara T, Ohtake S, Yasui M, Uemura K, Yoneyama S, Hattori Y, Teranishi JI, Yokomizo Y, Uemura H, Miyamoto $\mathrm{H}$ and Yao M: Low-molecular-weight protein tyrosine phosphatase expression as a prognostic factor for men with metastatic hormone-naive prostate cancer. Urol Oncol 35(10): 607.e609-607.e614, 2017.

25 P.A. H: Who clasification of tumors of the prostate. 138-162, 2016.

26 Aoun F, Albisinni S, Henriet B, Tombal B, Van Velthoven R and Roumeguere T: Predictive factors associated with biochemical recurrence following radical prostatectomy for pathological $t 2$ prostate cancer with negative surgical margins. Scand J Urol 51(1): 20-26, 2017

27 Lee S, Jeong CW, Jeong SJ, Hong SK, Choi W, Byun SS and Lee SE: The prognostic value of pathologic prostate-specific antigen mass ratio in patients with localized prostate cancer with negative surgical resection margins. Urology 82(4): 865-869, 2013.

28 Andersson J, Rosestedt M and Orlova A: Imaging of her2 may improve the outcome of external irradiation therapy for prostate cancer patients. Oncol Lett 9(2): 950-954, 2015.

29 Muniyan S, Chen SJ, Lin FF, Wang Z, Mehta PP, Batra SK and Lin MF: Erbb-2 signaling plays a critical role in regulating androgen-sensitive and castration-resistant androgen receptorpositive prostate cancer cells. Cell Signal 27(11): 2261-2271, 2015.

30 Tobiume M, Yamada Y, Nakamura K, Aoki S, Zennami K, Kato Y, Nishikawa G, Yokoi T and Honda N: Significant prognostic factor of immunohistochemical her-2 expression using initial prostate biopsy specimens with $\mathrm{m} 1 \mathrm{~b}$ prostate cancer. Prostate 71(4): 385-393, 2011.

31 Igawa T: Role of protein phosphatases in genitourinary cancers. Int J Urol 24(1): 16-24, 2017.

32 Igawa T: Analysis of the regulately mechanisms of androgenindependent prostate cancer using prostate-specific tyrosine phosphatase. Journal of the West Japan Urological Association 69(4): 197-203, 2007.

33 Alonso A, Sasin J, Bottini N, Friedberg I, Friedberg I, Osterman A, Godzik A, Hunter T, Dixon J and Mustelin T: Protein tyrosine phosphatases in the human genome. Cell 117(6): 699-711, 2004.

34 Ramponi G and Stefani M: Structure and function of the low mr phosphotyrosine protein phosphatases. Biochim Biophys Acta 1341(2): 137-156, 1997.
35 Chiarugi P, Cirri P, Raugei G, Camici G, Dolfi F, Berti A and Ramponi G: Pdgf receptor as a specific in vivo target for low $\mathrm{m}(\mathrm{r})$ phosphotyrosine protein phosphatase. FEBS Lett 372(1): 49-53, 1995.

36 Taddei ML, Chiarugi P, Cirri P, Buricchi F, Fiaschi T, Giannoni E, Talini D, Cozzi G, Formigli L, Raugei G and Ramponi G: Beta-catenin interacts with low-molecular-weight protein tyrosine phosphatase leading to cadherin-mediated cell-cell adhesion increase. Cancer Res 62(22): 6489-6499, 2002.

37 Lee JK, Edderkaoui M, Truong P, Ohno I, Jang KT, Berti A, Pandol SJ and Gukovskaya AS: Nadph oxidase promotes pancreatic cancer cell survival via inhibiting jak2 dephosphorylation by tyrosine phosphatases. Gastroenterology 133(5): 1637-1648, 2007.

38 Rigacci S, Talini D and Berti A: Lmw-ptp associates and dephosphorylates stat5 interacting with its c-terminal domain. Biochem Biophys Res Commun 312(2): 360-366, 2003.

39 Rigacci S, Rovida E, Bagnoli S, Dello Sbarba P and Berti A: Low $\mathrm{m}(\mathrm{r})$ phosphotyrosine protein phosphatase activity on fibroblast growth factor receptor is not associated with enzyme translocation. FEBS Lett 459(2): 191-194, 1999.

40 Chiarugi P, Cirri P, Marra F, Raugei G, Camici G, Manao G and Ramponi G: Lmw-ptp is a negative regulator of insulin-mediated mitotic and metabolic signalling. Biochem Biophys Res Commun 238(2): 676-682, 1997.

41 Kikawa KD, Vidale DR, Van Etten RL and Kinch MS: Regulation of the epha2 kinase by the low molecular weight tyrosine phosphatase induces transformation. J Biol Chem 277(42): 39274-39279, 2002.

42 Parri M, Buricchi F, Taddei ML, Giannoni E, Raugei G, Ramponi G and Chiarugi P: Ephrina1 repulsive response is regulated by an epha2 tyrosine phosphatase. J Biol Chem 280(40): 34008-34018, 2005.

43 Brantley-Sieders DM, Caughron J, Hicks D, Pozzi A, Ruiz JC and Chen J: Epha2 receptor tyrosine kinase regulates endothelial cell migration and vascular assembly through phosphoinositide 3-kinase-mediated rac1 gtpase activation. J Cell Sci 117(Pt 10): 2037-2049, 2004.

44 Pasquale EB: Eph receptor signalling casts a wide net on cell behaviour. Nat Rev Mol Cell Biol 6(6): 462-475, 2005.

45 Gleason DF: Classification of prostatic carcinomas. Cancer Chemother Rep 50(3): 125-128, 1966.

46 Epstein JI, Egevad L, Amin MB, Delahunt B, Srigley JR and Humphrey PA: The 2014 international society of urological pathology (isup) consensus conference on gleason grading of prostatic carcinoma: Definition of grading patterns and proposal for a new grading system. Am J Surg Pathol 40(2): 244-252, 2016.

47 Lattouf JB and Saad F: Digital rectal exam following prostatectomy: Is it still necessary with the use of psa? Eur Urol 43(4): 333-336, 2003.

48 Pound CR, Christens-Barry OW, Gurganus RT, Partin AW and Walsh PC: Digital rectal examination and imaging studies are unnecessary in men with undetectable prostate specific antigen following radical prostatectomy. J Urol 162(4): 1337-1340, 1999.

Received December 24, 2018

Revised January 7, 2019

Accepted January 17, 2019 